\title{
GAHARU DAN POTENSINYA DALAM PENGEMBANGAN EKOWISATA \\ DI NUSA TENGGARA BARAT
}

\section{GAHARU AND ITS POTENCY OF ECOTOURISM DEVELOPMENT IN WEST NUSA TENGGARA}

\author{
Robert Siburian \\ Lembaga Ilmu Pengetahuan Indonesia \\ E-mail: robertsdes1970@gmail.com
}

\begin{abstract}
ABSTRAK
Gaharu adalah produk hasil hutan bukan kayu yang beraroma wangi. Provinsi Nusa Tenggara Barat merupakan salah satuh tempat tumbuhnya pohon penghasil gaharu itu. Di dunia ini, terutama di Timur Tengah, masyarakat Arab adalah orang yang paling banyak untuk mengonsumsi gaharu. Permintaan gaharu pada satu sisi sangat tinggi, tetapi gaharu yang dihasilkan oleh pohon penghasil gaharu di hutan alam relatif jarang, hal itu membuat harga gaharu di pasara menjadi mahal. Petani pohon penghasil gaharu di Nusa Tenggara Barat tidak dapat memenuhi permintaan karena produk gaharu dari hutan alam sangat sedikit. Dalam menjawab tingginya permintaan terhadap gaharu alam, para petani mengembangkan budidaya pohon penghasil gaharu. Pohon penghasil gaharu ditanam di pekarangan dan kebun mereka, dan setelah beberapa tahun pohon gaharu diinokulasi dengan inokulan sebagai cara untuk mendapatkan resin yang aromatik. Pengembangan perkebunan gaharu yang dilakukan oleh petani dapat menjadi tujuan wisata potensial di Nusa Tenggara Barat untuk menambah daya tarik wisata yang sudah ada. Melalui tulisan ini, saya ingin menjelaskan mengapa perkebunan gaharu dan semua kegiatan yang mengikutinya menjadi daya tarik wisata potensial yang akan meningkatkan kesejahteraan petani gaharu di Nusa Tenggara Barat, terutama di Pulau Lombok.
\end{abstract}

Kata Kunci: Gaharu, Petani, Budidaya, Ekoturisme, Nusa Tenggara Barat

\section{ABSTRACT}

Agarwood is a fragrant non-wood product. West Nusa Tenggara is a site for growing agarwood tree. In the world, especially in the Middle East, the Arabian people are the most consumptive to agarwood. For demand to agarwood is high but the agarwood in forest is rarely, making the price of agarwood in the market is expensive. Agarwood farmers in West Nusa Tenggara could not be able to supply the demand because agarwood product from natural forest is very little. In answering the high demand to natural agarwood, the farmers develop agarwood cultivation. Agarwood trees were planted in theirs yards and gardens, and after some years the agarwood trees inoculated with inoculation as a way to get aromatic resin. Developing agarwood plantation of farmer can become a potential tourism destination in West Nusa Tenggara to add preexisting tourist attraction. Through this paper, I would like to explain why agarwood plantation and all activities following it become a potential tourism attraction which will improve welfare of agarwood farmers in West Nusa Tenggara, especially in Lombok Island.

Keywords: Agarwood, Farmer, Cultivation, Ecotourism, West Nusa Tenggara 


\section{PENDAHULUAN}

Tujuan dari tulisan ini adalah upaya menjelaskan potensi gaharu di Nusa Tenggara Barat dan kontribusinya dalam pengembangan ekowisata di wilayah itu. Dengan tujuan itu, pemanfaatan gaharu dari sisi ekonomi dan sosial terpenuhi di satu sisi, dan ekologi tempat tumbuhnya pohon penghasil gaharu itu terpelihara baik, di sisi lain.

Gaharu sebagai komoditi bernilai jual tinggidi pasar global, dapat menjadi komoditi untuk meningkatkan kesejahteraan masyarakat lokal, salah satu melalui pembangunan ekowisata berkelanjutan. Gaharu yang merupakanhasil hutan bukan kayu (HHBK), adalah salah satukomoditi yang masuk dalam daftar CITES (Convention on International Trade in Endangered Species of Wild Fauna and Flora atau konvensi perdagangan internasional tentang tumbuhan dan satwa liar spesies terancam) Appendix II. Oleh sebab itu, penangkapan gaharu dari hutan alam dan peredarannya harus memperoleh izin dan didasarkan pada kuota. Meskipun demikian, pohon penghasil gaharu dapat menjadi destinasi wisata menarik jika dikemas dalam atraksi pariwisata yang dapat mendatangkan wisatawan mancanegara.

Mengingat pohon penghasil gaharu yang semakin tipis di Provinsi Nusa Tenggara Barat, atraksi wisata yang mungkin disuguhkan terkait gaharu adalah pengembangan pohon penghasil gaharu budidaya. Hal itu mungkin dilakukan karena meskipun mekanisme peredaran gaharu yang diharuskan dalam daftar CITES Appendix II berdasarkan kuota, keharusan itu tidak menyurutkan masyarakat penggiat gaharu untuk tidak terlibat mengakses komoditas itu. Bagi masyarakat lokal penggiat gaharu, komoditi itu dapat memengaruhi ekonominya secara signifikan.

Posisi Nusa Tenggara Barat yang berlokasi di daerah segitiga emas dari empat daerah pariwisata utama di Indonesia, yaitu: Bali di bagian barat, Tanah Toraja (Sulawesi Selatan) dan Bunaken (Sulawesi Utara) di bagian utara, Pulau Komodo (Nusa Tenggara Timur) di bagian timur (Saufi, 2014) (Lihat Gambar 1), menjadi modal untuk mengembangkan pariwisata di wilayah itu, terutama dari sisi ekoturisme ditambah bahwa Nusa Tenggara Barat sebagai destinasi wisata telah dicanangkan sejak tahun 1979 (Saufi, 2014). Dalam hal pengembangan ekoturisme di Nusa Tenggara Barat, pohon penghasil gaharu dapat menjadi salah satu atraksi wisata potensial yang mungkin dikembangkan bermodalkan posisi geografis tadi. Malaysia sejak tahun 2012, termasuk negara yang sudah memanfaatkan potensi pohon penghasil gaharu sebagai destinasi agro-wisata menarik, yaitu The Gaharu Tea Valey, yang berlokasi di Gopeng, Distrik Kampar, negara bagian Perak, Malaysia (Mohamed, et al., 2018).

Secara umum bahwa definisi baku tentang ekoturisme belum ada atau belum diterima, karena ekoturisme dapat dilihat sebagai suatu aktivitas, bisnis, filosofi, perangkat pemasaran, simbol, atau seperangkat prinsip dan tujuan (Wight, 2001). Meskipun demikian, berdasarkan seleksi terhadap definisi ekoturisme yang dilakukan oleh Blamey (2001), disebutkan bahwa ada lima sumber yang coba mendefinisikan ekoturisme, yaitu: CeballosLascuráin pada tahun 1987, The Ecotourism Society pada tahun 1991, Ecotourism Association of Australia pada 1992, National Ecotourism Strategy of Australia pada tahun 1994), dan terakhir adalah Tickell tahun 1994.

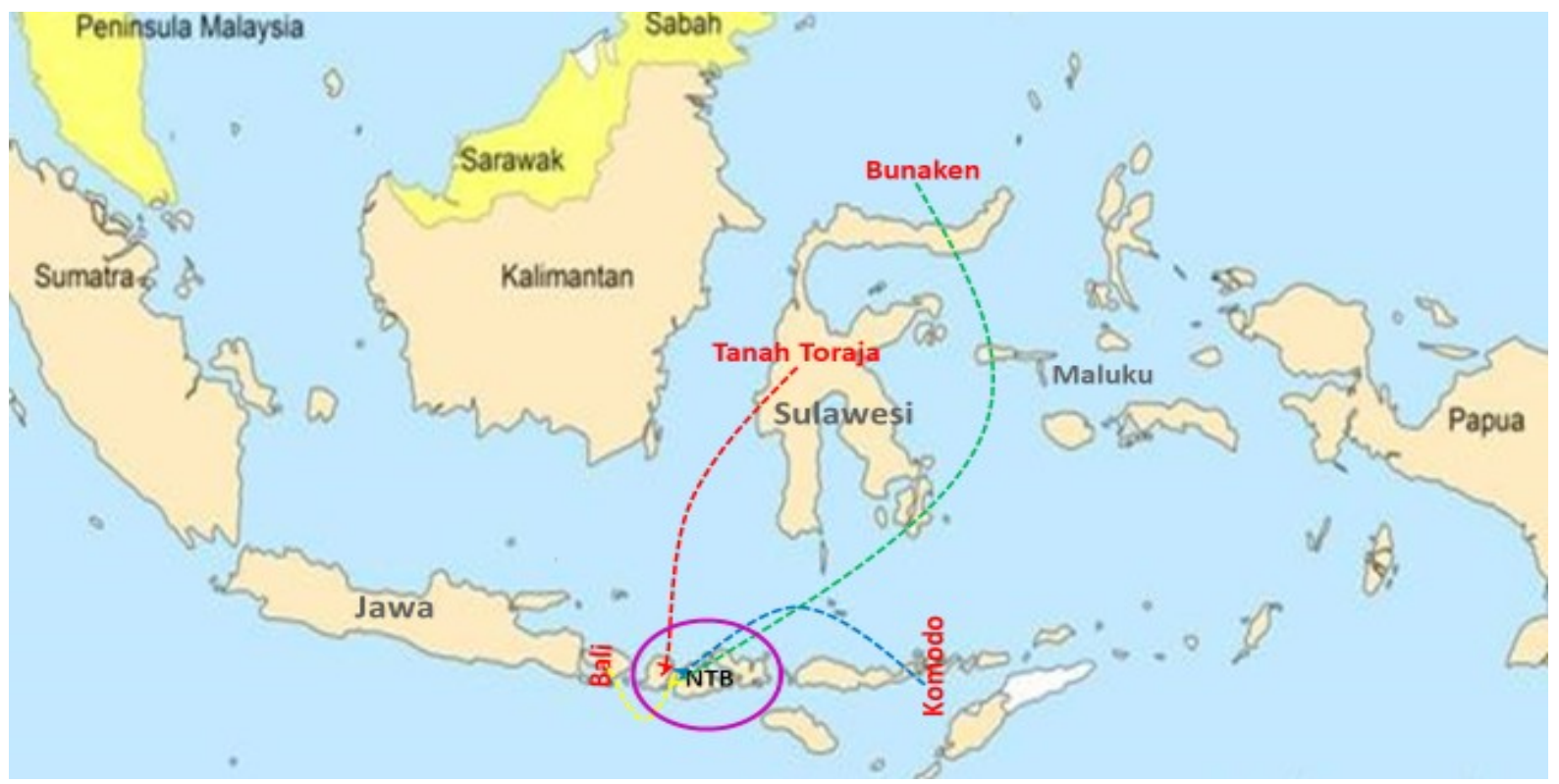

Gambar 1. Posisi Nusa Tenggara Barat yang berada di daerah segitiga emas dari empat daerah pariwisata utama di Indonesia. Sumber: Data diolah, 2018. 
Berdasarkan definisi pada masing-masing sumber itu, secara tegas dinyatakan bahwa ekoturisme itu didasarkan pada alam. Blamey (2001) juga menyebutkan bahwa konsep ekoturisme menekankan pada tiga dimensi utama, yaitu 1) berfokus pada alam (a focus on nature), 2) pengelolaan yang berkelanjutan (sustainable management), dan 3) pendidikan lingkungan (environmental education). Dengan kata lain, ekoturisme itu merupakan tanggunga jawab mereka yang melakukan perjalanan wisata terhadap kelestarian suatu lingkungan dan juga keberlangsungan masyarakat lokal di sekitar lingkungan yang menjadi tujuan wisata (tourism destination) dimaksud. Partisipasi masyarakat lokal dalam kegiatan ekoturisme menjadi elemen penting.

Menurut Hetzer (1965), dikutip oleh Blamey (2001), ada empat prinsip yang menjadi tanggung jawab ekoturisme, yaitu: 1) meminimalkandampak lingkungan, 2) menghormati kebudayaan milik masyarakat lokal yang menjadi tujuan wisata, 3) memaksimalkan manfaat yang dapat diberikan pada masyarakat lokal, dan 4) memaksimalkan kepuasan para wisatawan itu sendiri. Dengan prinsip itu, ekoturisme selain memberi dampak positif pada masyarakat lokal dengan meningkatnya pendapatan ekonomi, lingkungan pun tidak mengalami kerusakan. Dalam hal ini, lingkungan dijaga agar tetap pada kondisi lestari dan menjadi salah satu atraksi yang ditawarkan pada para turis. Ekoturisme menjadi mati ketika lingkungan yang akan dikunjungi oleh wisatawan mengalami kerusakan.

Secara sosial dan lingkungan pun, ekoturisme dapat dianggap sebagai bertumbuhnya sekelompok masyarakat yang melakukan kegiatan wisata, yang tadinya mereka adalah sekedar kelompok pengonsumsi barang, kemudian bergeser menjadi pengonsumsi makna (meaning), atau sekelompok orang yang mau belajar, ataupun mereka yang dalam liburannya terlibat secara sosial dan lingkungan di tempat mereka bertamasya (Wight 2001). Dengan kata lain, ekowisata tidak sekedar bertamasya, tetapi lebih daripada itu adalah sebuah pengalaman.

Munculnya konsep ekoturisme pada tahun 1980, menurut Travis (1982) dikutip oleh Khah, et al. (2011) adalah karena kegiatan pariwisata konvensional dinilai banyak pihak menimbulkan dampak negatif, seperti polusi, kerusakan ekosistem, meningkatnya urbanisasi, hilangnya flora dan fauna, dan rusaknya sumberdaya yang dapat diwariskan pada generasi berikutnya. Dengan konsep ekoturisme itu, dampak negatif yang timbul dari kegiatan pariwisata konvensional itu coba diminimalisir sehingga sumberdaya pariwisata yang menjadi destinasi dalam kegiatan ekowisata dapat dimanfaatkan secara berkelanjutan.

\section{METODE PENELITIAN}

Data yang dibutuhkan dalam tulisan ini adalah data primer dan data sekunder. Untuk memperoleh data primer, metode pengumpulan data dilakukan dengan wawancara mendalam ke berbagai informan, antara lain: petani, pengepul, dan pengusaha lokal gaharu. Selain itu, wawancara mendalam juga dilakukan pada staff di instansi yang menangani gaharu seperti Balai Konservasi Sumber Daya Alam (BKSDA) Nusa Tenggara Barat, Badan Penelitian dan Pengembangan Hasil Hutan Bukan Kayu Nusa Benggara Barat, dan akademisi di Universitas Mataram. Diskusi grup terfokus (Focus Group Discussion-FGD) juga dilakukan di Mataram untuk melengkapi data yang diperoleh dalam wawancara mendalam tersebut. Pihak yang diundang dalam FGD itu adalah pengusaha, staff dari intansi terkait, pengusaha lokal, dan akademisi. Sementara data sekunder diperoleh dengan studi literatur dan laporan-laporan terkait gaharu yang diterbitkan dan dipublikasikan oleh instansi terkait.

Pulau Lombok di Provinsi Nusa Tenggara Barat merupakan salah satu dari dua pulau besar di Provinsi Nusa Tenggara Barat, selain Pulau Sumbawa. Pulau yang berada di antara Pulau Bali di sebelah barat dan Pulau Sumbawa di bagian timur, Pulau Lombok memiliki luas sekitar $5.435 \mathrm{~km} 2$, atau 26,97\% dari seluruh wilayah daratan Provinsi Nusa Tenggara Barat yang mencapai 20.153,15 km2. Meskipun luas wilayah daratan Pulau Lombok lebih kecil dibandingkan Pulau Sumbawa yang mencapai 15.448 km2, penduduk di Pulau Lombok justru lebih padat dibandingkan dengan Pulau Sumbawa. Hal itu disebabkan Pulau Lombok menjadi pusat perekonomian sekaligus pusat pemerintahan Provinsi Nusa Tenggara Barat dengan ibukota Mataram.

Pulau Lombok yang terbagi menjadi empat kabupaten dan satu kota, yaitu Lombok Timur, Lombok Barat, Lombok Tengah, Lombok Utara, dan Kota Mataram (Lihat Gambar 2); dihuni penduduk sekitar 3.434.708 jiwa, padahal jumlah penduduk provinsi ini pada tahun 2016 hanya 4.896.162 jiwa. Dengan kata lain, sekitar 70,15\% dari jumlah penduduk Nusa Tenggara Barat berada di Pulau Lombok. Oleh sebab itu, tingkat kepadatan penduduk di Pulau Lombok sangat tinggi mencapai 632 jiwa/km2, sementara di Pulau Sumbawa hanya 95 jiwa/km2. 


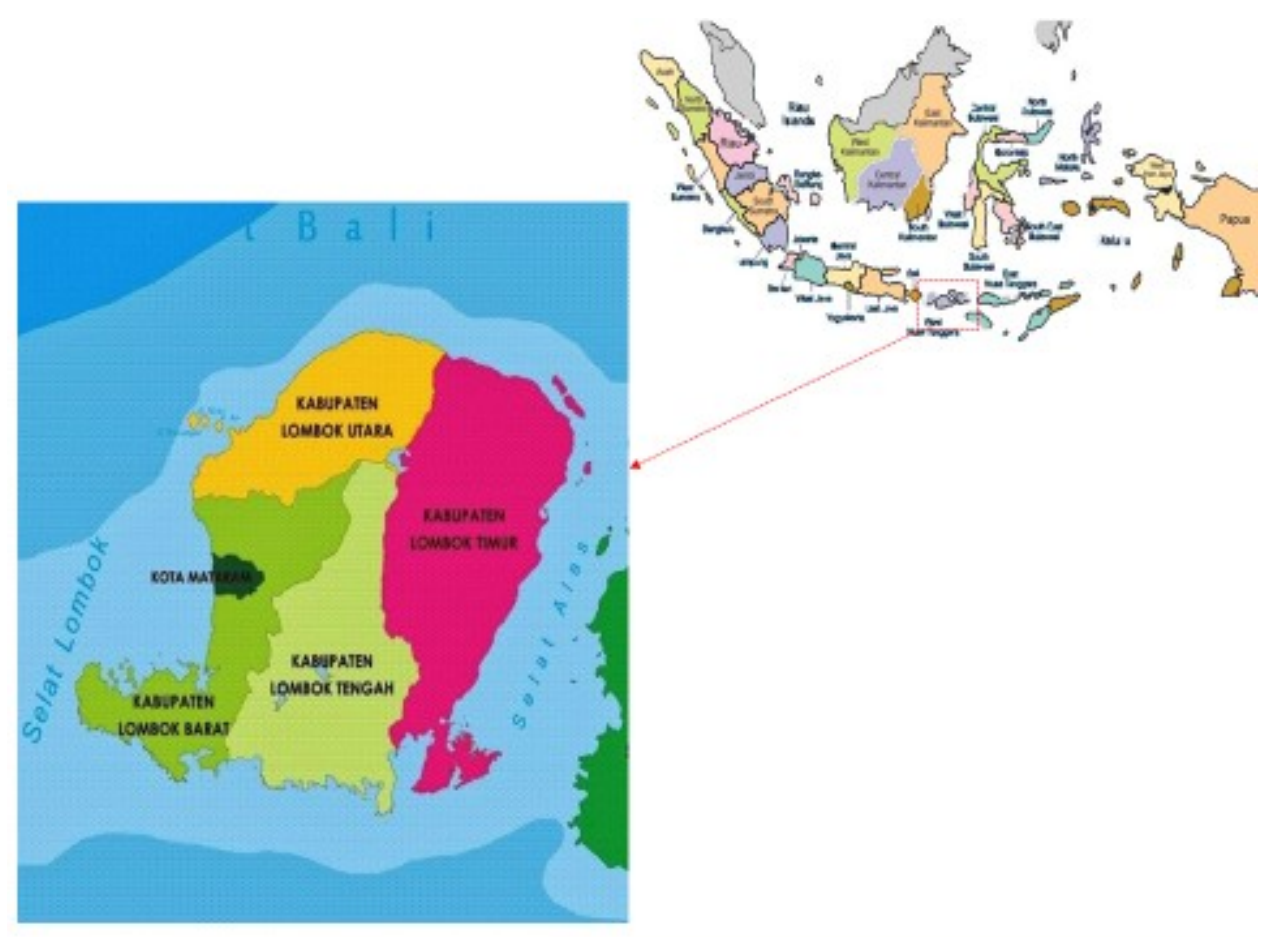

Gambar 2. Posisi Pulauy Lombok dalam Peta Wilayah Indonesia. Sumber: https://www.google.co.id

Berdasarkan pengamatan di lapangan, tingkat kepadatan penduduk di Pulau Lombok sangat tinggi. Kondisi itu terlihat dari permukiman yang juga padat dan rumah-rumah penduduk yang berlapis-lapis. Dengan demikian, kepadatan penduduk yang mencapai $632 \mathrm{jiwa} / \mathrm{km} 2$ hanya di atas kerta, karena karena tidak seluruh daratan yang ada di Pulau Lombok dapat dihuni dengan berbagai alasan, seperti tingkat kemiringan lahan yang tinggi dan pemanfaatan lain seperti Taman Nasional Gunung Rinjani, Taman Wisata Alam Kerandangan, Taman Wisata Alam Suranadi, Taman Wisata Alam Bangko-bangko, Taman Wisata Alam Pelangan, Taman Wisata Alam Gunung Tunak, dan Taman Wisata Alam Tanjung Tampa. Keberadaantaman nasional dan taman wisata alam itu, akan mengurangi ruang yang seharusnya dapat dihuni oleh penduduk di Pulau Lombok. Realitas kawasan hutan di Pulau Lombok relatif sedikit, hal itu memberi kontribusi jumlah gaharu alam yang berasal dari pulau itu relatif sedikit.

Daratan Pulau Lombok lebih sedikit dibandingkan Pulau Sumbawa, akan tetapi luas lahan pertanian terutama sawah, baik yang menggunakan irigasi maupun tidak jauh lebih luas di Pulau Lombok yang berbentuk relatif bulat tersebut. Data 2016 menunjukkan bahwa jumlah sawah di Pulau Lombok mencapai 130.335 hektar dari 1.904.110 hektar sawah yang ada. Pulau Sumbawa justru unggul di padi ladang dengan luas mencapai 48.566 hektar dari 62.108 padi ladang yang dimiliki oleh Provinsi Nusa Tenggara Barat.

\section{Pengenalan dan Persebaran Gaharudi Nusa Tenggara Barat}

Awal gaharu dikenal oleh masyarakat Lombok khususnya dan Nusa Tenggara Barat umumnya, diperkenalkan oleh orang Arab yang banyak bermukim di Ampenan. Magenda (2005) menyebutkan bahwa keberadaan orang Arab di Ampenan, dikenal sebagai 'Kota Tua',disebut juga 'Kota Lama' di Kota Mataram, sudah sejak abad 18 dan 19. Ampenan adalah kawasan yang dikembangkan pada tahun 1800-an sebagai pelabuhan strategis. Tumbuh sebagai kota kosmopolitan pada masa itu dengan kelompok masyarakat terdiri atas Cina, Arab, Melayu, dan Bugis. Pemerintah kolonial Belanda merancang kawasan ini terdiri dari pelabuhan, gudang-gudang barang, permukiman, areal pertokoan dan beberapa sarana pendukung lainnya. Dengan demikian, Ampenan tumbuh menjadi kota pelabuhan dan pusat perdagangan. Ampenan ramai hingga tahun 1976 sebelum Pemerintah Mataram memindahkan pelabuhan ke Lembar (Hartawan dan Ruwaidah, 2018). Selanjutnya, Kota Tua Ampenan ditetapkan sebagai kawasan cagar budaya merujuk pada Peraturan Daerah No. 12 tahun 2011 tentang RTRW Kota Mataram Tahun 2011-2031. Mereka umumnya menjadi pedagang danpenyiar agama Islam. Orang Arab itumengenalkan gaharu pada petani (masyarakat lokal) sekitar tahun 1970-an karena orang Arab membutuhkan gaharu untuk keperluan sehari-hari, termasuk untuk dibawa ke negara asalnya di Timur Tengah. Oleh karena komoditas itu tidak begitu dikenal oleh masyarakat Nusa Tenggara Barat, harga gaharu yang diperkenalkan oleh orang Arab itu seadanya saja, sangat jauh di bawah harga saat ini.

Pada tahun 1970-an itu, masyarakat Nusa Tenggara Barat diminta oleh orang Arab untuk mencari gaharu di dalam hutan. Pada masa itu, gaharu yang dibudidayakan belum ada sehingga gaharu yang ada masih harus dicari di dalam hutan alam. Dengan demikian, gaharu yang dijual kepada orang Arab adalah gaharu 
berkualitas tinggi. Pohon penghasil gaharu pun diseleksi sedemikian rupa, yaitu hanya bagian-bagian pohon yang mengandung gubal gaharu saja yang dipotong. Pemotongan terhadap seluruh pohon gaharu baru dilakukan setelah seluruh pohon diperkirakan mengandung gubal gaharu. Gaharu dijual kepada orang Arab dalam bentuk bakulan, tidak seperti sekarang dalam satuan kilogram. Setiap satu bakul gaharu, beratnya sekitar 7 kilogram, ditukar dengan beras sebanyak satu karung dengan berat sekitar 10 kilogram. Artinya, setiap satu kilogram gaharu dihargai hanya sekitar 1,43 kilogram beras. Pada saat itu, pertukaran gaharu berlangsung dalam bentuk barter. Jika harga dollar Maret 2018 adalah USD 13.500 dan harga beras paling bagus adalah Rp 11.000 per kilogram, sehingga harga beras pada tahun 1970 pada saat kurs dollar terhadap rupiah sekitar Rp 328/USD 1 adalah Rp 267 perkilogram. Dengan kata lain, harga gaharu per kilogram yang dibarter dengan beras sekitar 1,43 kilogram adalah Rp 381,81,-. Jika harga gaharu sekarang yang ada di Desa Gegerung untuk kelas super mencapai Rp 70.000.000,- harga itu meningkat sangat cepat sekitar 183.337 kali di atas harga gaharu pada tahun 1970-an tersebut. Apabila harga emas pada tahun 1970-an sekitar Rp 13.922 per gram, maka peningkatan harga emas pada Maret 2018 yang mencapai 573.000 per gram atau naik sekitar 41 kali, masih jauh lebih rendah dibandingkan harga kenaikan gaharu itu.

Sebagai salah satu daerah penghasil gaharu alam, Provinsi Nusa Tenggara Barat mendapat kuota gaharu untuk diedarkan dari wilayah itu mulai tahun 2003. Pemberian kuota dimaksud merupakan regulasi yang ada dalam CITES (Convention on International Trade in Endangered Species of Wild Fauna and Flora atau konvensi perdagangan internasional tentang tumbuhan dan satwa liar spesies terancam), bertujuan agar peredaran dan perdagangan gubal gaharu dapat dikontrol. Dengan kata lain, izin dari otoritas resmi dibutuhkan untuk peredaran dan perdagangan, termasuk ekspor/impor gaharu. Sejak tahun 2016 sampai 2018, pemerintah memberikan kuota gaharu dari Nusa Tenggara Barat sebanyak $4.500 \mathrm{~kg}$ (4,5 ton). Kuota itu sesungguhnya sudah mengalami penurunan dari tahun-tahun sebelumnya, yaitu $5.000 \mathrm{~kg}$ pada tahun 2013-2015; $9.500 \mathrm{~kg}$ tahun 2012; $8.000 \mathrm{~kg}$ pada tahun 2007-2011; bahkan kuota itu pernah mencapai $10.000 \mathrm{~kg}$ pada tahun 2006.Pada kurun waktu itu (2006 sampai 2015), kuota gaharu yang diberikan pada Provinsi Nusa Tenggara Barat selalu terpenuhi meskipun perusahaan yang memiliki izin edar hanya satu unit saja. Hanya saja, gaharu yang diedarkan untuk memenuhi kuota dimaksud tidak sepenuhnya berasal dari wilayah Provinsi Nusa Tenggara Barat, tetapi juga gaharu yang diperoleh (dibeli) dari daerah lain seperti Kalimantan dan Papua (Hasil wawancara dengan En, staf BKSDA Provinsi Nusa Tenggara, pada hari Selasa, 8 Mei 2018).

Penyebab menurunnya kuota gaharu dari Nusa Tenggara Barat adalah sulitnya menemukan gaharu alam dari hutan Nusa Tenggara Barat akibat populasi pohon penghasil gaharu (Gyrinops) yang terus menurun seiring maraknya pemburuan gaharu karena harganya yang begitu tinggi di pasar global. Hal itu mendorong eksploitasi gaharu alam yang dilakukan tidakmengindahkan kelestariannya.Padahal, tidak semua pohon penghasil gaharu memproduksi gaharu (Barden, Anak, Mulliken, dan Song, 2000) dan butuh waktu lama untuk menghasilkan gubal gaharu. Untuk mendapatkan gaharu dari sebuah pohon penghasil gaharu, harus diawali dengan terjadinya luka pada pohon dimaksud, baik luka melalui proses alami maupun akibat intervensi manusia. Luka itu berfungsi sebagai media jamur untuk masuk dan menyerang bagian gubal kayu dan bertumbuh di sana membentuk gubal-gubal gaharu.

Kuota gaharu alam dari Nusa Tenggara Barat tahun 2016 sampai 2018 jumlahnya menurun. Meskipun demikian, kuota dimaksud tidak pernah terealisasi jika didasarkan pada data tertulis semata. Hal itu disebabkan satu-satunya perusahaan yang memiliki izin edar gaharu di Provinsi Nusa Tenggara Barat sudah tutup seiring dengan meninggalnya pemilik usaha dimaksud. Padahal dalam kenyataan, peredaran gaharu alam di Nusa Tenggara Barat masih signifikan, hanya saja peredaran gaharu dimaksud tidak terdata karena tidak melalui jalur resmi. Dalam buku Provinsi Nusa Tenggara Barat Dalam Angka yang diterbitkan oleh Badan Pusat Statistik setiap tahun,data tentang gaharu tidak ada. Sebagai contoh, data gaharu yang berada diurutan 15(lima belas) dari lima belas jenis produksi hasil hutan bukan kayu yang tercantum dalam Provinsi Nusa Tenggara Dalam Angka tahun 2017 adalah nihil (nol) (BPS 2017).

Secara umum, gaharu yang dihasilkan oleh pohon jenis Gyrinops tumbuh baik di Provinsi Nusa Tenggara Barat, baik yang berada di Pulau Lombok maupun Pulau Sumbawa. Terlihat dari Gambar 3 bahwa sebaran gaharu alam di Pulau Lombok hanya berada di dua titik, sementara di Pulau Sumbawa sebarannya masih relatif lebih banyak. Sebaliknya, sebaran gaharu budidaya di Pulau Lombok lebih banyak dibandingkan sebaran yang terdapat di Pulau Sumbawa. 


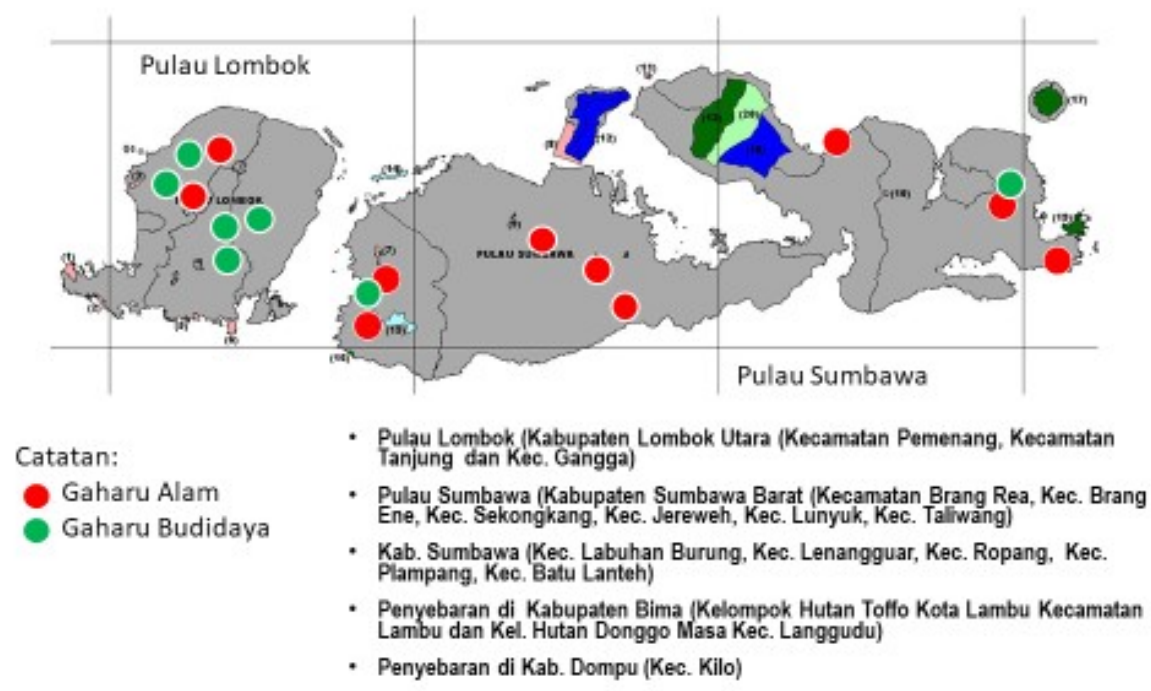

Gambar 3. Sebaran Pohon Penghasil Gaharu Alam dan Budidaya di Provinsi Nusa Tenggara Barat. Sumber: Balai KSDA Provinsi Nusa Tenggara Barat, Mei 2018

Selain luas kedua pulau jauh berbeda, Pulau Lombok luasnya hanya 4.738,65 Km2 dan Pulau Sumbawa luasnya mencapai $15.414,5 \mathrm{Km} 2$, sebaran pohon penghasil gaharu juga dipengaruhi oleh tingkat kepadatan penduduk dan luas kawasan hutan yang masih tersisa. Jumlah penduduk Provinsi Nusa Tenggara Barat pada tahun 2016 adalah 4.896.162 jiwa, sekitar 70,15\% berada di Pulau Lombok dan sisanya sekitar 29,85\% berada di Pulau Sumbawa (BPS 2017). Luas kawasan hutan di Provinsi Nusa Tenggara Barat dari semua jenis hutan meliputi hutan suaka alam, hutan konservasi (taman nasional, taman wisata alam, taman hutan rakyat, dan taman buru), hutan lindung, hutan produksi (hutan produksi terbatas dan hutan produksi tetap) mencapai 1.071.722,83 hektar; sekitar 84,76\% atau 908.429,86 hektar di antaranya berada di Pulau Sumabawa, sedangkan sisanya sekitar 15,24\% atau 163.342,97 hektar berada di Pulau Lombok (Dinas LHK, 2017). Dengan kawasan hutan di Pulau Sumbawa yang relatif luas, kecenderungan untuk tumbuh dan ditemukannya tanaman hutan penghasil gaharu jenis Gyrinops akan lebih tinggi dibandingkan di Pulau Lombok.

Harga gaharu yang begitu tinggi, tidak berarti komoditi ini menarik investor untuk berinvestasi membuat perkebunan gaharu. Hal itu terlihat dari perkebunan pohon penghasil gaharu yang ada di Provinsi Nusa Tenggara Barat tidak ada yang dilakukan oleh perusahaan besar, kecuali perkebunan rakyat saja. Berbeda dengan komoditi lain seperti karet, coklat, kelapa sawit, ataupun hutan tanaman industri yang banyak diminati oleh investor. Dua alasan utama yang mendasari tidak berminatnya investor menanamkan modalnya untuk membudidaya pohon penghasil gaharu. Pertama, tingkat spekulasi yang begitu tinggi terhadap pohon penghasil gaharu budidaya. Meskipun pohon penghasil gaharu sudah diinjeksi dengan menginokulasi pohon tersebut, tidak ada jaminan $100 \%$ bahwa pohon yang diinokulasi itu berhasil menghasilkan gubal gaharu, sebab gubal gaharu yang dihasilkan sangat tergantung pada jamur inokulan yang disuntikkan. Ada kemungkinan pohon penghasil gaharu yang sudah diinokulasi menjadi mati. Berdasarkanpenelusuran berbagai literatur dan wawancara dengan berbagai informan, tidak ada jamur inokulan yang menjadi standar agar pohon penghasilo gaharu ketika dilakukan intervensi melalui inokulasi dijamin menghasilkan gubal gaharu. Apabila pohon penghasil gaharu busuk ataupun tidak menghasilkan gubal gaharu, pohon itu sama dengan pohon lainnya bahkan tidak dapat dimanfaatkan sebagai bahan bangunan misalnya, karena jenis pohon itu lunak sekali. Kedua, terkait didaftarkannya gaharu dalam CITES Appendix II. Hal itu menyebabkan gubal gaharu yang akan diedarkan harus terlebih dahulu memperoleh izin dari institusi pemegang otoritas resmi. Selain itu, gubal gaharu yang diperdagangkan (diedarkan) berdasarkan kuota yang sudah dibagi-bagi pada masing-masing provinsi.

\section{HASIL DAN PEMBAHASAN}

Uraian berikut menjelaskan potensi gaharu sebagai atraksi wisata yang dapat disuguhkan pada para wisatawan yang berkunjung ke Provinsi Nusa Tenggara Barat. Uraian itu dilanjutkan dengan keberadaan gaharu pada saat ini yang sudah memberikan kontribusi positif bagi para petani tetapi belum menjadi perhatian pemerintah daerah untuk menjadikannya sebagai sebuah komoditi prioritas.

\section{Potensi Gaharu sebagai Atraksi Wisata: dari Penanaman sampai Pemanenan}

Provinsi Nusa Tenggara Barat merupakan salah satu destinasi wisata alam di Indonesia. Obyek wisata yang sudah dikenal oleh wisatawan mancanegara antara lain Pantai Senggigi, Gili Trawangan, dan Gunung Rinjani. Dewasa ini sedang dikembangkan kawasan wisata unggulan di provinsi itu, yang diberi nama Kawasan 
Ekonomi Khusus (KEK) Mandalika. KEK Mandalika yang berada di bagian Selatan Pulau Lombok dan menghadap Samudera Hindia, ditetapkan melalui Peraturan Pemerintah Nomor 52 Tahun 2014 untuk menjadi KEK Pariwisata, dengan luas areal 1.035,67 ha.

Pada tahun 2012, Pemerintahan Indonesia mencanangkan 12 daerah wisata yang bersahabat bagi umat Muslim (Moslem friendly destination). Penetapan Moslem friendly destination itu untuk mengakomodir keberadaan gelombang baru dari pariwisata yang dikenal dengan 'Wisata Halal' (Halal Tourism) atau "Wisata Sharia" (Sharia Tourism). Keduabelas provinsi yang dimaksud adalah Aceh, Sumatera Barat, Riau, Lampung, Banten, Jakarta, Jawa Barat, Jawa Timur, Jawa Tengah, Yogyakarta, West Nusa Tenggara Barat dan Sulawesi Selatan. Pertimbangan menetapkan daerah-daerah itu sebagai tujuan wisata yang bersahabat bagi umat Muslim didasarkan pada kunjungan wisatawan ke daerah itu didominasi dari negara-negara berpenduduk mayoritas Muslim seperti Arab Saudi, Brunei Darussalam, Mesir, dan Negara-negara Timur Tengah lainnya (Firdausi, 2017).

Provins Nusa Tenggara Barat sebagai salah satu dari 12 provinsi sebagai daerah wisata yang bersahabat bagi umat Muslim, mengakomodirnya dalam bentuk Peraturan Daerah Provinsi Nusa Tenggara Barat Nomor 2 Tahun 2016 tentang Pariwisata Halal. Dalam Pasal 1 Ayat 16 dari Perda, dijelaskan bahwa: "Pariwisata Halal adalah kegiatan kunjungan wisata dengan destinasi dan industri pariwisata yang menyiapkan fasilitas produk, pelayanan, dan pengelolaan pariwisata yang memenuhi syari,ah". Perbedaan pariwisata konvensioanl sebagai usaha-usaha wisata yang menjual jasa dan produk kepariwisataan yang tidak berpatokan pada prinsip-prinsip syari'ah, maka pariwisata halal berpatokan pada prinsip-prinsip syari'ah seperti yang ditetapkan oleh Dewan Syariah Nasional Majelis Ulama Indonesia DSN-MUI.

Sebelum Provinsi Nusa Tenggara Barat menerbitkan pariwisata halal dalam bentuk peraturan daerah (Perda), negara-negara di Timur Tengah sesungguhnya sudah mengakui Provinsi Nusa Tenggara Barat sebagai tujuan wisata yang bersahabat bagi Muslim. Pada tahun 2015 misalnya, Nusa Tenggara Barat meraih dua penghargaan World Hotel Travel Award 2015 dari Uni Emirat Arab, yaitu sebagai The World's Best Halal Tourism Destination dan The World's Best Halal Honeymoon Destination. Dengan penghargaan yang diraih itu, pemerintah provinsi sebenarnya sudah dimudahkan untuk mempromosikan Nusa Tenggara Barat ke negaranegara Muslim lain guna menjaring wisatawan agar lebih banyak berkunjung ke Nusa tenggara barat itu. Kemudian, setelah Nusa Tenggara Barat menjadi tujuan wisata Halal di dunia, jumlah kunjungan wisata ke provinsi itu menunjukkan peningkatan, sehingga pada tahun 2016 kunjungan wisatawan muslim mencapai dari atau 600.000 orang atau $20 \%$ dari 3 juta orang wisatawan (Anonim, 2017).

Menjadikan gaharu sebagai bagian dari atraksi wisata, dimaksudkan untuk menambah obyek wisata yang dapat dikunjungi oleh para wisatawan, terutama wisatawan yang berasal dari Tiongkok dan Timur Tengah yang menjadi pasar bagi gaharu yang berasal dari Provinsi Nusa Tenggara Barat. Mengembangkan gaharu sebagai salah satu atraksi wisata, dimaksudkan untuk mendekatkan para wisatawan, terutama yang berasal dari Timur Tengah dan negara-negara Islam lainnya, terkait dengan komoditi gaharu yang erat dengan kehidupan mereka sehari-hari. Sebab, gaharu (dalam bahasa Arab dikenal dengan oudh) merupakan komoditi penting sebagai bagian dari kehidupan masyarakat di Timur Tengah. Gaharu mereka pergunakan sebagai aromatik tradisional dan parfum dalam berbagai bentuk: dari kayu bermutu tinggi dalam bentuk serpihan (chip) dibakar oleh Syekh untuk menghormati tamu yang datang berkunjung, wangi pakaian pribadi sebelum acara-acara khusus dandalam persiapan untuk doa, hingga memberikan aroma wangi dalam rumah tangga secara umum. Kwalitas gaharu yang digunakan itu menunjukkan status sosial dan gengsi seseorang ataupun keluarga tersebut. Selain itu, gaharu pun dilihat sebagai bagian dari warisan serta identitas nasional modern (Antonopoulou, et al., 2010).

Gaharu merupakan hasil hutanbukan kayu yang sangat menjanjikan secara ekonomi karena nilai jualnya tinggi. Oleh sebab itu, gaharu diburu sampai jauh ke tengah hutan. Bahkan, pemburuan gaharu tidak saja lintas pulau dalam satu provinsi, tetapi juga lintas pulau antarprovinsi, sehingga para pemburu gaharu alam dari Pulau Lombok misalnya, tidak saja memburu gaharu ke Pulau Sumbawa sebagai bagian dari wilayah Provinsi Nusa Tenggara Barat, tetapi ada juga yang mencarinya hingga ke hutan pedalaman di Pulau Kalimantan dan Papua.

Masifnya pemburuan gaharu alam yang ditandai dengan eksploitasi yang dilakukan secara terus menerus dan berlebihan tanpa perhitungan, mengakibatkan jumlah populasi dan mutu produksi gaharu dari Provinsi Nusa Tenggara Barat sudah sangat menurun, selain tehnik pemanenan yang tidak tepat, proses penularan masih secara alami, dan belum banyak dilakukan penanaman (Surata dan Soenarno, 2011). Dengan kata lain, langkah yang berorientasi konservasi gaharu di alam liar tidak dilakukan oleh pelaku gaharu, kendati tidak semua pengusaha bersikap sama, yang ada di Nusa Tenggara Barat, karena pelaku gaharu masih bersedia membeli gaharu hasil memburu dari hutan alam meskipun volume gaharu yang diperoleh tidak begitu banyak. Haji Kadir misalnya, selaku pemilik usaha PT. Segarang Alam Lestari sekaligus pemegang izin edar gaharu di Provinsi Nusa Tenggara Barat sejak Maret 2017, tidak membeli gaharu alam dari para pencari gaharu sebab apabila itu dilakukan, yang dikhawatirkan adalah populasi gaharu di hutan alam semakin habis

Penurunan populasi gaharu di hutan alam sementara permintaan terhadap gaharu begitu tinggi, menjadi sebuah masalah sekaligus tantangan. Penurunan gaharu dari hutan alam itu beririsan dengan tutupan hutandi 
wilayah Nusa Tenggara Barat yang semakin menipis. Sejatinya, luas hutan di provinsi ini mencapai 1,7 juta hektar atau 53\% dari luas daratan NTB, akan tetapi luas areal yang tertutup oleh hutan hanya $21 \%$ di Pulau Lombok tinggal 21\% dan 18\% saja di Pulau Sumbawa. Apabila tidak dilakukan terobosan upaya pelestarian pohon penghasil gaharu, kemungkinan besar pohon penghasil gaharu itu akan lenyap. Alternatif budidaya pohon penghasil gaharu menjadi salah satu solusinya. Kondisi hutan di Nusa Tenggara Barat itu disampaikan oleh Ridha Hakima (2017), Koordinator WWF Nusa Tenggara, saat berdiskusi dengan pimpinan DPRD NTB terkait dengan masalah kehutanan, Selasa (7 Maret 2017), bersama dengan pejabat Dinas PU NTB, Dinas Lingkungan Hidup dan Kehutanan serta BPBD NTB

Terhadap pohon penghasil gaharu budidaya, lokasi itu dapat dijadikan sebagai destinasi wisata, termasuk perlakuan (treatment) yang diberikan pada pohon itu. Para wisatawan dapat diundang untuk mengunjungi lokasi-lokasi penanamam pohon penghasil gaharu dan mekanisme menginokulasi pohon penghasil gaharu. Atraksi ini menjadi menarik karena prosesnya dapat dilihat oleh wisatawan secara langsung. Mereka tidak lagi hanya menerima gaharu dalam bentuk gubal ataupun produk turunannya. Memang, kesiapan lahan dengan tanaman pohon penghasil gaharu di dalamnya untuk dijadikan contoh pohon penghasil gaharu budidaya harus tersedia.

Pohon penghasil gaharu budidaya sesungguhnya sudah signifikan untuk meningkatkan kesejahteraan masyarakat, meskipun komoditi gaharu belum menjadi unggulan dan belum dijadikan sebagai atraksi pariwisata. Tingkat kesejahteraan yang meningkat itu terlihat pada rumah-rumah yang ditempati petani gaharu di Desa Gegerung yang terus membaik. Desa Gegerung, Kecamatan Lingsar, Kabupaten Lombok Barat menjadi miniatur dari keberhasilan petani gaharu. Rumah-rumah penduduk yang sebelumnya sangat sederhana, tetapi dengan adanya komoditi gaharu, secara perlahan rumah sederhana itu dapat mereka bangun agar lebih permanen, meskipun pembangunannya dilakukan secara bertahap. Dengan kata lain, pengembangan rantai nilai komoditas gaharu dapat menjadi alternatifpengurangan angka kemiskinan di Provinsi Nusa Tenggara Barat, yang sebelumnya didahului dengan merumuskan program aksi yang siapuntuk diimplementasikan kepada masyarakat sesuai dengan kekuatan dan kelemahan,peluang dan ancaman yangterdapat hampir disetiap rantai nilainya, mulai dari proses perencanaandan desain produk; pembibitan; penanaman danpemeliharaan; teknologi penggubalan; panendan pasca panen; transformasi produk danpemasaran sampai pada konsumen akhir (Siddik, 2010).

Petani dalam membudidayakan pohon penghasil gaharu, bibit pohon itu ada yang dibeli dari petani yang membibitkannya seharga Rp 2.000 untuk bibit setinggi $40 \mathrm{~cm}$ dan Rp 25.000 untuk tinggi $100 \mathrm{~cm}$. Meskipun demikian, bibit pohon penghasil gaharu ada juga yang diperoleh dari orang yang membibitkannya secara 'gratis'. Hanya saja, mereka yang menerima bibit 'gratis' untuk ditanam di lahannya, apabila waktu menginokulasi sudah tiba setelah 3 sampai 4 tahun sejak ditanam, yang melakukan inokulasi adalah pemberi bibit tersebut. Setelah dua sampai tiga tahun sejak inokulasi dilakukan, jika panen sudah waktunya maka hasilnya dibagi antara petani dengan pemberi bibit dan penginokulasi itu. Sebelum inokulan dilakukan maka batang pohon harus dibor terlebih dahulu agar isolat (jamur) yang akan dimasukkan ke dalam pohon mempunyai saluran sehingga pohon lebih cepat menyerapnya. Jumlah lubang hasil pemboran dalam satu pohon bervariasi, tergantung keinginan karena tidak ada standar yang mengaturnya.

\section{Ikon yang tidak Menjadi Prioritastetapi Mengangkat Kesejahteraan Petani}

Gaharu menjadi salah satu sumber pendapatan ekonomi keluarga bagi petani gaharu di Provinsi Nusa Tenggara Barat.Gaharu sudah lama menjadi komoditi global,harganyadi pasar internasional begitu tinggi. Harga hingga US\$2 juta per kg dalam bentuk serpihan kayu (wood-chips) telah dicatat untuk gaharu dengan kualitas tertinggi (Report of the Asian Regional Workshop, 2015). Jensen (2003) menyebutkan bahwa gaharu dari hutan alam memiliki kualitas tinggi dibandingkan dengan gaharu hasil budidaya. Hal itu senada dengan informasi yang disampaikan oleh para petani gaharu di Pulau Lombok.

Mengingat populasi pohon penghasil gaharu di hutan alam semakin tipis, sementara permintaan global begitu tinggi, petani di Lombok pun coba membudidayakannya. Usaha pembibitan gaharu dimulai sejak berlangsung proyek pengembangan gaharu sekitar tahun 1998/1999 di Hutan Senaru seluas 225 hektar. Hutan Senaru tujuan proyek itu kemudian dikukuhkan menjadi Hutan Pendidikan yang dikelola oleh Universitas Mataram berdasarkan Surat Keputusan Menteri Kehutanan Nomor: SK.392/Menhut-II/2004 tanggal 18 Oktober 2004 (Fauzi, 2010). Pada awalproyek pembibitan dimulai, pihak Universitas Mataram membina beberapa orang untuk membantu membibitkan gaharu dalam rangka mememenuhi kebutuhan proyek itu (Siddik, 2010).

Budidaya pohon gaharu mutlak dilakukan sebagai bentuk respon terhadap semakin langkanya gaharu yang diproduksi oleh hutan alam dan semakin tingginya harga gaharu di pasar internasional (Jensen, 2003). Jika budidaya tidak dilakukan, pohon penghasil gaharu yang tersisa di hutan alam akan segera habis.

Realitas kondisi permintaan gaharu saat ini, yang laku dijual tidak hanya gubal saja tetapi juga gaharupalsu (fake agarwood) guna memenuhi permintaan pasar dari masyarakat kelas menengah ke bawah yang ada di Timur Tengah. Gaharu palsu, dalamperdagangannyadiberinamaBlack Magic Wood (BMW), dimodifikasi sesuai bentuk asli gubal gaharu, diprosesdarikayu putih yang tidak mengandung gaharu sama sekali namun 
masih jenis pohon penghasil gaharu (gyrinops). Harga komoditi itu bervariasi antara Rp 150.000 sampai Rp 1 juta setiap kilogram, tergantung tingkat kesulitan dalam proses pengerjaan yang dilakukan oleh para pengrajin. Dengan kata lain, terciptanya gaharu buatan yang dihasilkan oleh para pengusaha gaharu buatan di Pulau Lombok merupakan hasil interaksi para pengusaha tersebut dengan para eksportir gaharu di Jakarta.Pengamatan kami di lapangan pada tanggal 18 Desember 2018, gaharu BMW ini banyak diperjualbelikan secara eceran di toko-toko yang ada di Mangga Dua Square, Jakarta.Harga BMW ini ada yang Rp 1,2 juta dan Rp Rp 2,5 juta per kilogram, tergantung pada aroma wangi yang dikeluarkann oleh gaharu palsu hasil suntikan itu (Hasil wawancara dengan Msy, pengusaha kayu gaharu, tanggal 13 Mei 2018).
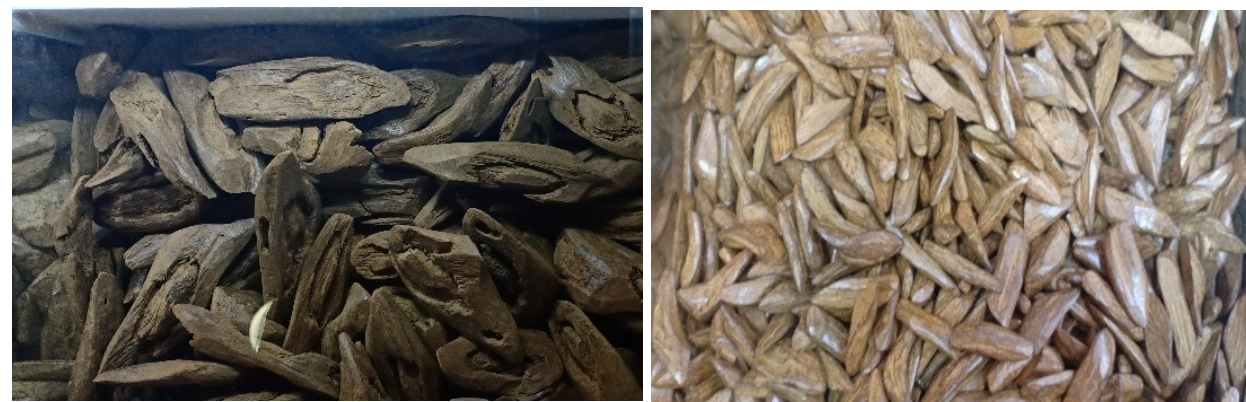

Gambar 4. Contoh gaharu buatan (BMW) yang diperjualbelikan di Mangga Dua Square, Jakarta. Sumber: Robert Siburian, koleksi pribadi, 18 Desember 2018.

Budidaya pohon penghasil gaharu yang dilakukan oleh masyarakat masih sporadis, bukan budidaya yang memperoleh arahan ataupun pembinaan dari pemerintah daerah. Penanaman pohon penghasil gaharu yang dilakukan oleh masyarakat, didasarkan pada inisiatif oleh masyarakat yang memiliki lahan untuk dikembangkan. Biasanya, pemilik lahan membangun kerja sama dengan pemilik modal meskipun bukan dalam skala besar. Kerja sama dengan pemilik modal itu adalah mereka menyuplai bibit pohon penghasil gaharu kepada petani pemilik lahan. Bibit pohon tersebut diberikan secara gratis, tetapi dengan satu syarat ketika usia pohon penghasil gaharu sudah waktunya untuk diinokulasi, pihak yang berhak menginokulasi adalah pemberi bibit tadi.

Gaharu yang sesungguhnya menjadi ikon dan sekaligus komoditi unggulan pada level masyarakat ataupun petani,ternyata tidakmenjadi komoditi prioritas dalam berbagai kebijakan pemerintah untuk dikembangkan. Padahal, komoditi ini sejatinya dapat dikembangkan untuk mengurangi kemiskinan di Provinsi Nusa Tenggara Barat yang jumlahnya mencapai 793.780 jiwa atau 16,21\% dari jumlah penduduk Nusa Tenggara Barat yang mencapai 4.896.200 jiwa pada tahun 20016 (BPS, 2017). Sesungguhnya, pada tahun 2007 , Kabupaten Lombok Barat sudah mencanangkan tanaman gaharu sebagai salah satu tumbuhan yang mendapat perlakuan khusus bersama 24 jenis tumbuhan lain. Jumlah penduduk miskin di Nusa Tenggara Barat itu memberi kontribusi sekitar 2,86\% pada jumlah penduduk miskin di Indonesia secara nasional, yang jumlahnya mencapai 27.771.240 jiwa atau 10,7\% dari jumlah penduduk sekitar 259.371.300 pada tahun 2016 (BPS, 2017). Pencanangan jenis tanaman unggulan itu tertuang dalam Surat Keputusan Bupati Nomor 62/314/Hutbun/2007. Surat keputusan tersebut menjadi dasar hukum untuk mengalokasikan anggaran daerah terhadap pengembangan gaharu dimaksud. Akan tetapi, implementasi surat keputusan yang dimaksud tidak secara nyata mengarah pada pohon penghasil gaharu. Perlakuannya tidak berbeda dengan tumbuhan jenis lain, meskipun peran gaharu untuk meningkatkan pendapatan ekonomi keluarga diberbagai desa di Kabupaten Lombok Barat sangat signifikan. Dengan maraknya pembudidayaan pohon penghasil gaharu tersebut, terutama di Desa Gegerung, penduduk menyebut desa mereka sebagai 'Desa Gaharu'.Meskipun surat keputusan dimaksud belum pernah dicabut, pengalokasian anggaran daerah yang secara khusus ditujukan untuk mengembangkan tumbuhan gaharu dimaksud masih nihil. Surat keputusan itu semakin tidak bermakna seiring pengambilalihan kewenangan pemerintah kabupaten/kota ke pemerintah provinsi terkait urusan masalah kehutanan sebagai implikasi dari Undang-undang Nomor 23 Tahun 2014 tentang Pemerintahan Daerah.

Dampak singnifikan bagi kesejahteraan para petani gaharu tampak dari rumah tinggal para petani gaharu yang semakin baik. Desa Gegerung, Kecamatan Lingsar, Kabupaten Lombok Barat misalnya, menjadi miniatur dari keberhasilan petani gaharu. Rumah-rumah penduduk yang sebelumnya sangat sederhana, tetapi dengan adanya komoditi gaharu, secara perlahan rumah sederhana itu dapat mereka bangun agar lebih permanen, meskipun pembangunannya dilakukan secara bertahap. Kondisi yang diuraikan ini sebelum terjadinya gempa yang melanda Pulau Lombok pada tanggal 29 Juli 2019 dengan kekuatan M 6,4 dan tanggal 5 Agustus 2019 dengan kekuatan M 7,0. Pasca kedua gempa itu, kondisi permukiman di Desa Gegerung mungkin saja sudah berubah akibat kerusakan yang diakibatkannya. Dengan kata lain, pengembangan rantai nilai komoditas gaharu dapat menjadi alternatifpengentasan kemiskinan di Provinsi Nusa Tenggara Barat, yang sebelumnya didahului dengan merumuskan program aksi yang siapuntuk diimplementasikan kepada masyarakat 
sesuai dengan kekuatan dan kelemahan,peluang dan ancaman yangterdapat hampir disetiap rantai nilainya, mulai dari proses perencanaandan desain produk; pembibitan; penanaman danpemeliharaan; teknologi penggubalan; panendan pasca panen; transformasi produk danpemasaran sampai pada konsumen akhir (Siddik 2010).

\section{KESIMPULAN DAN SARAN}

Budidaya pohon penghasil gaharu sangat mungkin dilakukan karena masyarakat yang ada di Pulau Lombok sudah mengenal pohon tersebut relative lama dan mampu membudidayakannya. Hanya saja, upaya untuk mendapatkan inokulan yang dapat menghasilkan gaharu berkwalitas tinggi agar dapat diterima pasar global harus terus digalakkan. Keterlibatan berbagai pihak termasuk pemerintah daerah menjadi penting, termasuk untuk menjadikan jenis tumbuhan itu sebagai tanaman unggulan sehingga pengalokasian anggaran untuk pengembangan pohon penghasil gaharu lebih jelas dan berkelanjutan.

Pembudidayaan pohon penghasil gaharu, selain bertujuan untuk menjamin keberadaan populasi pohon penghasil gaharu di hutan alam dan tidak punah akibat eksploitasi yang berlebihan karena sudah digantikan oleh pohon penghasil gaharu budidaya, adalah juga untuk meningkatkan kesejahteraan petani. Sebab, banyak petani yang sudah menikmati hasil dari pohon penghasil gaharu yang berhasil diinokulasi.

Nusa Tenggara Barat dengan ditetapkannya sebaga daerah tujuan wisata halal, dapat menawarkan pembudidayaan pohon penghasil gaharu sebagai salah satu atraksi wisata. Hal itu beralasan karena wisatawan yang disasar dengan penerapan wisata halal tersebut adalah masyarakat yang berasal dari Timur Tengah yang juga menjadi konsumen yang menikmati gaharu yang berasal dari Nusa Tenggara Barat. Atraksi wisatawan yang ditawarkan dapat dalam bentuk paket, yaitu selain perkebunan pohon penghasil gaharu yang hijau sekaligus juga proses penginokulasian pohon penghasil gaharu untuk terbentuknya gubal gaharu.

\section{DAFTAR PUSTAKA}

Anonim. 2017. “Kunjungan Wisatawan Muslim Capai 20 Persen”. http://suarantb.com. Diakses, 15 Oktober 2018.

Antonopoulou, M., J. Compton, L. S. Perry, dan R. Al-Mubarak. 2010. The trade and use of agarwood (Oudh) in the United Arab Emirates. Petaling Jaya, Selangor, Malaysia: TRAFFIC Southeast Asia.

Barden, A., N. A. Anak, T. Mulliken, dan M. Song. 2000. Heart Of The Matter: Agarwood Use And Trade And Cites Implementation for Aquilaria Malaccensis. Cambridge : TRAFFIC International.

Blamey, R. K. 2001. "Principles of Ecotourism”. Dalam D. B. Weaver (Editor)The Encyclopedia of Ecotourism. London: CABI Publishing.Hlm.: 5-22.

BPS. 2017. Provinsi Nusa Tenggara Barat Dalam Angka.Mataram: BPS Provinsi Nusa Tenggara Barat.

Dinas LH dan K. 2017. Statistik Dinas Lingkungan Hidup dan Kehutanan Provinsi NTB Tahun 2016. Mataram: Dinas Lingkungan Hidup dan Kehutanan Provinsi Nusa Tenggara Barat.

Fauzi, T. 2010. Pengembangan Gaharu di Universitas Mataram. Makalah disampaikan pada kegiatan magang isolasi, inokulasi bibit gubal dan kultur jaringan pembibitan tanaman gaharu, kerjasama Fakultas Pertyanian Universitas Mataram dan Pemerintah Kabupaten Sorong, Mataram 28 Juni s.d 5 Juli 2010.

Firdausi, I., S. Marantika, Z. N. Firdaus , R. Sajidah. 2017. "Lombok: Halal Tourism as a New Indonesia Tourism Strategy". Makalah disampaikan pada4th International Conference on Humanities, Social Sciences and Education (ICHSSE-17) March 13-14, 2017 Dubai (UAE). Prossiding. Hlm.: 53-57.

Hartawan, T., dan E. Ruwaidah. 2018. "Pemetaan dan Identifikasi Bangunan Bersejarah di Kota Tua Ampenan Mataram Nusa Tenggara Barat”. DalamSangkareang Mataram 4(1): 41-46.

Jensen, A. 2003. Domestication of aquilaria spp. and rural poverty-socio-economic and genetic aspect of the planting boom in the "wood of the gods". NAFRI Workshop Proceedings Shifting Cultivation and Poverty Eradication In The Uplands Of The Lao PDR, 233-239.

Khah, S. A., R. J. Rao, K. A. Wani. 2011. "Ecotourism and the Impact of the Conventional Tourism on the Fragile Ecosystems". Dalam International Journal of Science and Nature 2(3): 432- 442.

Magenda, B. D. 2005. "Dinamika Peranan Politik Keturunan Arab di Tingkat Lokal". Dalam Antropologi Indonesia29( 2): 182-197.

Mohamed, Z., S. H. M. Afandi, S. Ramachandran, A. Shuib, dan P. Kunasekaran. 2018. “Adventure Tourism In Kampar, Malaysia: Profile And Visit Characteristics Of Domestic Visitors". DalamBusiness and Society 19: $175-185$. 
Report of the Asian Regional Workshop on the Management of Wild and Planted Agarwood Taxa, Guwahati, Assam, India, 19-23 January 2015.

Ridha Hakima. 2017. "Kondisi Hutan di NTB Memprihatinkan". http:/globalfmlombok.com/read/2017/03/08/ kondisi-hutan-di-ntb-memprihatinkan .html. Diakses, 3 Agustus 2018.

Saufi, A., F. Teguh, H. Ristanto, P. Basuki, O. Oehms, D. Vitriani, S. Creutz, B. H. Nuzullay. 2014. Sustainable Tourism Master Plan for Lombok 2015-2019: Executive Summary. Lombok: Badan Perencanaan dan Pembangunan Daerah Provinsi Nusa Tenggara Barat.

Siddik, M. 2010."Pengembangan Rantai Nilai Komoditas Gaharu sebagai Alternatif Pengentasan Kemiskinan di Provinsi Nusa Tenggara Barat". Agroteksos Vol. 20 No.2-3, Desember 2010: 144-153.

Surata, I. K. dan Soenarno. 2011. "Penanaman Gaharu (Gyrinops Versteegii (Gilg.) Domke)) dengan Sistem Tumpangsari di Rarung, Provinsi Nusa Tenggara Barat. Dalam Jurnal Penelitian dan Konservasi Alam 8(4): 349-361.

Wight, P. A. 2001. "Ecotourists: Not a Homogeneous Market Segment”.Dalam D. B. Weaver (Editor)The Encyclopedia of Ecotourism. London: CABI Publishing: 37-62. 